\title{
O PROTAGONISMO DA EDUCAÇÃO ESCOLAR INDÍGENA COM O POVO KANINDÉ DE ARATUBA-CE
}

\author{
THE PROTAGONISM OF INDIGENOUS SCHOOL EDUCATION WITH THE \\ KANINDÉ PEOPLE OF ARATUBA-CE
}

\author{
Roberto Kennedy Gomes Franco ${ }^{1}$ \\ Francisco Wallison Batista de Lima ${ }^{2}$
}

\section{RESUMO}

Esse artigo sobre o protagonismo da educação escolar indígena com o Povo Kanindé de Aratuba/CE é desdobramento de nossa experiência com dois projetos de iniciação científica PIBIC/FUNCAP e PIBIC/UNLAB, realizado entre os anos de 2015 e 2017, nos quais, dialeticamente, analisamos as histórias da educação escolar indígena no Ceará como lugar de ancestralidade, interculturalidade e resistência étnica. A investigação se processa no âmbito do debate teórico-metodológico desenvolvido pelo campo interdisciplinar da História da Educação, ampliando sujeitos, temas e objetos. Metodologicamente, nos situamos na zona de interseção de fontes (orais, escritas e audiovisuais). Entretanto, o foco central são as narrativas do trabalho educativo desenvolvido pelos docentes e lideranças indígenas do Povo Kanindé de Aratuba/CE. Historicamente, a educação escolar indígena diferenciada, focada no respeito aos saberes ancestrais desses povos, tendo o bilinguismo, a interculturalidade e a especificidade enquanto sustentáculos essenciais do trabalho educativo, é fruto da luta e resistência dos movimentos sociais organizados dos povos indígenas. Estrategicamente, esta consciência étnica se faz na luta pela terra expropriada, que remonta ao processo brutal de genocídio e etnocídio em nome da fé e da ganância mercantilista colonial em diante, pela identidade negada, mas não apenas, este fazer-se, desigual e combinado, evidencia-se também como território de descolonização da educação escolar indígena, estabelecida por ampla legislação educacional pós-1988, com a Constituição.

PALAVRAS-CHAVE: Protagonismo; História da Educação; Indígenas.

\begin{abstract}
This article on the role of indigenous school education with the Kanindé of Aratuba / CE People is a reflection of our experience with two scientific initiation projects PIBIC / FUNCAP and PIBIC / UNLAB, carried out between 2015 and 2017, in which, dialectically, we analyze the stories of indigenous school education in Ceará as a place of ancestry, interculturality and ethnic resistance. The research is carried out within the framework of the theoretical-methodological debate developed by the interdisciplinary field of the History of Education, expanding subjects, themes and objects. Methodologically, we are located in the intersection zone of sources (oral, written and audiovisual). However, the central focus is the narratives of the educational work developed by the teachers and indigenous leaders of the Kanindé People of Aratuba/CE. Historically, differentiated indigenous school education, focused on respect for the ancestral knowledge of these peoples, having bilingualism, interculturality and specificity as essential supporters of educational work, is the fruit of the struggle and resistance of the organized social

\footnotetext{
${ }^{1}$ Professor da Universidade da Integração Internacional da Lusofonia Afro-Brasileira - UNILAB. Pós-Doutor em História da Educação pela Universidade de Lisboa. Doutor em Educação Brasileira/UFC; Mestre em Ciências da Educação/UFPI e Graduado em História/UFC. Coordenador do Grupo de Investigação Marxista - GIM. Membro do Grupo de Estudo com os Povos Indígenas - GEPI. E-mail: robertokennedy@unilab.edu.br

${ }^{2}$ Bacharel em Humanidades pela Universidade da Integração Internacional da Lusofonia Afro Brasileira - UNILAB. Discente do curso de História da UNILAB. Membro do Grupo de Estudo Com Povos Indígenas - GEPI.E-mail: wallisonbatistalima@ outlook.com
} 
movements of indigenous peoples. Strategically, this ethnic consciousness is made in the struggle for expropriated land, which goes back to the brutal process of genocide and ethnocide in the name of faith and colonial mercantilist greed onwards, for the identity denied, but not only, this becoming, unequal and combined, is also evidenced as the territory of decolonization of indigenous school education, established by extensive educational legislation post-1988, with the Constitution.

KEYWORDS: Protagonism; History of Education; Indigenous people.

\section{INTRODUÇÃO}

Por vezes, são os professores indígenas aqueles que conviveram com consciência crítica e profética os problemas de uma comunidade ou de seu Povo, de tal modo que a escola tem sido o lugar em que se originaram movimentos de resistência e de reivindicação de direitos sobre a terra, contra a discriminação e a falta de respeito. (BARTOMEU MELIÀ, 1999, p.15)

Este artigo acerca do protagonismo da educação escolar indígena com o Povo Kanindé de Aratuba/CE é desdobramento de nossa experiência com dois projetos de iniciação científica - PIBIC/FUNCAP e PIBI/UNLAB - realizados entre os anos de 2015 e 2017 sobre as histórias da educação escolar indígena no Ceará como lugar de ancestralidade, interculturalidade e resistência étnica.

Dialeticamente, a investigação emerge do debate teórico-metodológico desencadeado pelo campo interdisciplinar da História da Educação, ampliando sujeitos, temas e objetos. Metodologicamente, nos situamos na zona de interseção de fontes (orais, escritas e audiovisuais). Entretanto, o foco central são as narrativas do trabalho educativo desenvolvido pelos docentes e lideranças indígenas do Povo Kanindé de Aratuba/CE.

Historicamente, a educação escolar indígena diferenciada, focada no respeito aos saberes ancestrais desses povos, tendo o bilinguismo, a interculturalidade e a especificidade enquanto sustentáculos essenciais do trabalho educativo, é fruto da luta e resistência dos movimentos sociais organizados dos povos indígenas.

Estrategicamente, esta consciência étnica se faz na luta pela terra expropriada, que remonta ao processo brutal de genocídio e etnocídio em nome da fé e da ganância mercantilista colonial em diante, pela identidade negada, mas não apenas, este fazer-se, desigual e combinado, evidencia-se também como território de descolonização da educação escolar indígena, estabelecida por ampla legislação educacional pós-1988, com a Constituição.

Diluída neste contexto, a Escola Diferenciada Manoel Francisco dos Santos situada na comunidade Fernandes do Povo Kanindé em Aratuba-CE, foi inaugurada em 2006. Ela conta com uma proposta de educação diferenciada que surge por pressões do movimento indígena em âmbito nacional, o qual reivindicava um modelo educativo que pautasse a ancestralidade, a 
memória e a cultura como base para a criação dos currículos e métodos de ensino, uma educação que respeitasse autonomia e diversidade dos povos indígenas.

Pensando a pluralidade e a diversidade como uma importante ferramenta para compreensão do processo de ensino e aprendizagem dos Kanindé, utilizamos a interdiciplinaridade, uma vez que, como nos descreve o IMES (2008, p.14) a Interdiciplinaridade significa "[...] a integração de dois ou mais componentes curriculares na construção do conhecimento [...]", com isso observamos ser necessário analisarmos essas pontes de ligações existentes entre a memória, a cultura e a identidade, e pensando como tudo isso se reflete na escola diferencida como médoto pedagógico de ensino. Foi possível perceber que a escola indígena se apresenta como esse terreno indiciplinar de contato, visto que dentro do seu currículo pedagógico se encontram saberes diversos, desde os ancestrais indígenas até os da modernidade.

Nessa perspectiva, optamos por usar os métodos de observação participante e a etnografia, dado que essas ferramentas são auxiliares para o entendimento das dinâmicas sociais e culturais vivenciada pelo grupo no cotidiano da comunidade, assim como o da escola, ou seja, nos possibilitou compreender a realidade desse povo, para assim levantarmos as informações desejadas. O método de revisão bibliográfica utilizado objetivou um resgate histórico dos povos sobre o processo histórico da educação escolar indígena no Brasil. Perpassando especificamente pelos Kanindé de ARATUBA-CE, foi perceptível em certos momentos da história essa semelhança existente do processo educativo em âmbito macro no Brasil para o micro no povo Kanindé.

As entrevistas com os professores também foram relevantes para a conquista desses resultados. Para tanto, decidimos entrevistar duas professoras pioneiras no ensino de história na instituição, a Professora Rita da Silva Alexandre e a Professora Ivoneice Bernardo da Silva. Entrevistamos também, os guardiões da memória dos Kanindé, como o Francisco Benardo da Silva (Senhô), 74 anos, José Maria Perreira dos Santos(Cacique Soterro),73 anos, e Cicero Perreira dos Santos, 64 anos(liderança).

Portanto, a partir dessas memórias educativas e da escola como um ponto de memória, é necessário compreendermos os processos históricos os quais passaram os agentes detentores da memória, como professores, alunos e lideranças, nesse sentido que Souza (1996, p.53) nos descreve que "torna-se necessário também tentar compreender a maneira com que professor e alunos reconstruíram suas experiências, [...] e a si próprios como sujeitos históricos". 
Para compreendermos a importância da memória para os Kanindé, é necessário que atentemos à construção social dessas memórias aqui descritas, pois é da memória que eles buscam subsídio para reafirmação de sua ancestralidade indígena. Nesse aspecto, Pollak fala em seu livro Memória e Identidade Social, ao tratar da problemática da construção social da memória, a partir das experiências vividas, uma vez que a memória é algo construindo socialmente e está sujeita a transformações. Dessa forma, as memórias dos Kanindé de Aratuba foram construídas socialmente, por meio das relações sociais praticadas no âmbito das afinidades étnicas e culturais exercidas e herdadas de seus ancestrais, memórias essas que sofrem influências e transformações, mas, que em sua essência, existem acontecimentos e símbolos que resistem.

Então, significa que a escola indígena é dialeticamente interpretada como lugar de ancestralidade, interculturalidade e resistência étnica.

\section{O MOVIMENTO INDÍGENA, PROTAGONISMO E A CONQUISTA EDUCATIVA}

A retomada do movimento indígena brasileiro surge por volta da década de 70 , porém podemos observar em outros momentos da história do Brasil que esses sujeitos sempre mantiveram o espírito da luta e da resistência, de acordo com Silva e Azevedo (1995), "foram as mais diversas formas de resistência, desde a resistência física, a diplomacia e a resistência cultural". Segundo ainda Silva e Azevedo (1995), há três motivos que impulsionaram a emergência da organização dos povos indígenas no Brasil, o primeiro foi que as populações indígenas viviam em uma situação estarrecedora, pois grande parte de seus territórios foram tomados ou violentados pelos colonizadores, que menosprezavam e desprezavam as tradições, cultura e a língua, como também os processos de ensino e aprendizagem dos nativos, colocando-os em patamares inferiores, levando assim a genocídios ${ }^{3}$ e etnocídios ${ }^{4}$ como importante ferramenta de dominação.

Outro argumento levantado pela autora é o próprio modelo político que estava sendo implementado pela Ditadura Militar, iniciada em 1964, uma vez que, nesse período, emergem inúmeros movimentos sociais que reivindicavam a saída da Ditadura. Nesse momento de organização social da nação e de luta pelo direito à democracia e aos direitos sociais, o

\footnotetext{
${ }^{3}$ Genocídio: significa o extermínio de pessoas tendo como principal motivação as diferenças de nacionalidade, raça, religião e, principalmente, diferenças étnicas, é uma prática que visa eliminar grupos étnicos minoritários em determinada espaço geográfico.

${ }^{4}$ Etnocídio: significa extermínio cultural de um determinado grupo étnico tendo como principal motivação as diferenças de nacionalidade, raça, religião e, principalmente, diferenças étnicas, é uma prática que visa eliminar a cultura de determinados grupos étnicos.
} 
movimento indígena também entra nesse processo com um foco principal: as demarcações dos territórios que foram arbitrariamente retirados das populações nativas.

De acordo com Silva e Azevedo (1995) a articulação em âmbito internacional dos povos indígenas brasileiros por meio de organizações que atuavam na garantia de direitos humanos, contribuiu para a aproximação de lutas com outros grupos indígenas da América latina como o Paraguai em 1974 e posteriormente com outros povos da Bolívia e Uruguai, essa relação internacional trouxe visibilidade às lutas dos povos indígenas e consequentemente a conquista de muitos direitos que historicamente foram negados a esses povos.

Sobre esse processo de surgimento do Movimento Indígena Munduruku (2012, p. 209) aponta que:

\begin{abstract}
O surgimento do movimento indígena brasileiro nasceu com a conjuntura política e social que eclodiu no Brasil a partir de 1970. Foram tempos difíceis, pois imperava em nosso pas o regime de exceção, preconizado pelos militares a partir de 1964. Naquela ocasião, a política indigenista do Governo previa que os povos indígenas deveriam ser integrados pela nação e, consequentemente, abrirem mão de suas identidades étnicas, para se tornarem "apenas" brasileiros. Essa política estava a serviço dos interesses de desenvolvimento e integração nacional, que também escondiam a intenção de explorar as riquezas presentes no solo subsolo das terras tradicionalmente ocupadas pelos por nossos povos.
\end{abstract}

Posteriormente, essa organização nacional foi se ramificando em todas as regiões da nação, as quais buscavam fortificar e conscientizar outros sobre a importância da organização e da luta para se conquistar direitos fundamentais como a vida, saúde, cultura, educação etc. Essa ampliação impulsiona o surgimento de inúmeros momentos deliberativos, como assembleias que reuniam indígenas de todas as regiões do Brasil, e de diversas etnias diferentes que colocavam suas contribuições para organização e fortificação da luta e das pautas, através dessas assembleias de acordo com Silva (1995) se consolidam várias entidades representativas dos indígenas tanto em âmbito nacional como regional e local, como também a criação de alianças com a sociedade civil favorável à causa indígena e aos movimentos sociais. Essas alianças foram de extrema importância como estratégia de luta, uma vez que o movimento indígena por meio das alianças conseguiu visibilidade política e social. Desta forma os indígenas foram construindo o seu protagonismo no decorrer da história. Sobre a visibilidade e negação do protagonismo indígena, Munduruku (2012, p.209) pondera que:

Do ponto de vista dos indígenas, os acontecimentos que os afetavam não tinham repercussão na mídia nacional, tornando-os isolados na luta pela defesa de seus direitos. Cada povo afetado pelas frentes de expansão acabava sendo vitimado por ondas de violências cada vez mais intensas e nocivas, sem ter consciência de que tal devastação cultural fazia parte da política desenvolvimentista patrocinada pelo capital internacional e executada pela recém-criada Fundação Nacional do Índio. O que 
poderia ter sido interpretado como alívio para nossos povos era, na verdade mais um golpe contra os interesses indígenas.

O texto acima nos leva a refletir sobre a importância da atuação coletiva dos índios dentro dessas organizações representativas, visto que a contribuição e o protagonismo coletivo dos inúmeros povos indígenas em várias regiões do Brasil foi essencial para a construção do grande movimento indígena no país, com uma organização inicial que nasce na região Norte e principalmente no estado do Amazonas e, posteriomente, ganha força em âmbito nacional, através de encontros que reuniam milhares de índios das mais diversas etnias diferentes, tanto em questões geográficas, culturais e línguísticas. Todavia, esse movimento heterogêneo conseguiu grandes avanços na questão educativa para os índios no Brasil, como uma educação realmente autônoma e diferenciada que respeitasse as tradições, a cultura e a identidade dos povos.

Para Silva e Azevedo (1995) o movimento dos professores indígenas foi de grande importância para a transformação do modelo educativo executado nas comunidades, uma vez que possibilitou, ao criarem e recriarem suas próprias formas de ensinar, a cultura a partir do contato com outros povos e com a sociedade brasileira, uma escola intercultural heterogênea que não reproduza preconceitos, mas que contribui para afirmação da diferença, que levanta a bandeira da interdisciplinaridade e da mutirreferencialidade para a construção de currículos plurais que reflitam a diversidade, e que se aproxime dos saberes ancestrais de cada povo, respeitando as singularidades de cada grupo étnico, sobre o papel do "professor indígena". Silva e Azevedo (1995, p. 158), especificam a expressão “professor indígena” sendo, “professores no sentido pleno, que são além da sala de aula que lecionan, onde ao mesmo tempo que são professores também baniwa, tikuna, guarani, Kanindé, Jenipapo-Kanindé etc., e que portanto se preocupam, enquanto professores,[...]," portanto, cada profissional desse tem a importante tarefa de conscientizar as novas gerações sobre afirmação da identidade e preservação das tradições do seu povo.

Em 1988, houve algumas conquistas do movimento indígena, embora que, na prática, não tenham acontecido mudanças reais, mas a aprovação da Constituição de 88 assegurou inúmeros direitos às populações indígenas no Brasil, como o direito fundamental à terra, à educação, à saúde, à cultura e à tradição, podemos observar que só se tornou possível a inclusão desses importantes direitos na Constituição através da organização dos indígenas. Nesse estágio, inicia-se outra grande luta para o movimento indígena, isto é, a implanção e as garantias dos direitos conquistados na Constituição Cidadã, que perdura até hoje, mas os índios resistem e lutam por seus direitos. Sabemos que foram muitas conquistas, entretanto é 
necessário reconhecermos muitas pautas a serem conquistadas. A terra se torna, ainda, um dos grandes problemas para as populações indígenas brasileiras, pois apesar da Constituição garanti-la como direito fundamental, os processos burrocráticos, prolongam por anos os processos jurídicos das demarcações, acirrando, a cada momento, os conflitos entre os índios e os grandes latifundiários, os quais invandem as terras índígenas e se apropriam de suas riquezas naturais.

\section{O POVO KANINDÉ E SEU PROCESSO EDUCATIVO}

Os primeiros movimentos educativos nos Kanindé iniciam em 1999, quando começaram articulações de reconhecimento dos índios Kanindé, os quais faziam reivindicações, juntamente com o movimento indígena, em âmbito nacional, pelos direitos de uma educação específica e diferenciada para suprir as necessidades educacionais do povo. Segundo Gomes (2016) enfrentaram então os primeiros passos para a conquista da tão sonhada escola que tinha como princípios a reafirmação da identidade do povo, como também alfabetização de crianças indígenas através da história e da oralidade ancestral Kanindé.

Martins e Santos (2015, p. 25) ponderam que o povo Kanindé buscava uma escola que:

[...] pudesse contribuir com continuidade da cultura do povo Kanindé e oferecer a alfabetização de qualidade para os jovens indígenas, para que todos tivessem possibilidade de conhecer a história da comunidade, as suas origens, por meio do acesso à educação escolar dentro da própria aldeia, provendo oportunidade e visão de futuro as futuras gerações Kanindé. Uma escola que nos ajudasse a desenvolver um projeto de formação educacional diferenciada e especifica para suprir as necessidades locais, uma "escola do nosso jeito" (Cacique Sotero), pois só assim os índios Kanindé poderiam amenizar o grande preconceito que assolava a comunidade vinda tanto de outros seguimentos da sociedade envolvente, como também da própria comunidade.

Inicialmente, a escola indígena funcionava nas casas dos próprios professores indígenas e das lideraças, de acordo Martins e Santos (2016, p. 25) a educação foi incentivada pelos docentes Suzenilton Santos, Terezinha Barrozo e a liderança Benicio Lourenço, após participarem de um seminário no CETREX (Centro de Treinamento em Extensão Rural), em Caucaia, sobre educação escolar indígena no Ceará no ano de 2003.

Segundo Ivoneice (Professora/2015), algumas vezes até embaixo de árvores as aulas aconteciam. Uma vez que não havia prédio para abrigar a escola, a demanda de alunos que procuravam a escola só crescia, isso por conta dos inúmeros casos de preconceito vivenciados pelas crianças indígenas nas escolas tradicionais, logo a demanda impulsionou a criação de duas salas de aulas, que foram construídas com os próprios recursos da comunidade. 
Segundo Bernardo (Liderança Indígena, janeiro, 2016) “[...] nós trabalhávamos homens, mulheres e meninos nessa época todos trabalhavam juntos, e nos fizemos o Colégio que hoje esse Colégio ainda tá, que ficava na parte de cima da comunidade onde ele ainda está de pé até hoje $[\ldots] "$ ".

Com o crescimento da demanda de alunos, foi preciso fazer uma diferenciação entre as salas de aulas e séries, as dificuldades eram grandes, uma vez que a comunidade não contava com um espaço adequado, foi preciso investir na construção de mais três salas, nas quais, por meio da divisão e ampliação, foi possível introdução do Ensino Fundamental e Médio. Sendo denominada de Escola de Ensino Fundamental de cima, e Médio Fernandes de baixo, a Escola Manoel Francisco dos Santos só foi possível por meio da organização das lideranças e da comunidade, as quais, observando o crescimento do número de alunos da escola indígena, resolveram organizar um movimento com apoio dos pais e professores para articular uma reunião na comunidade com a presença do Secretario Municipal de Educação e da Secretária Regional de Educacação- CRED 8 de Baturité. Nas inúmeras negociações a pauta sempre era a construção de um prédio adequado às necessidades da comunidade, levando dados para esses órgãos a necessidade de implantação de uma escola diferenciada que atendesse pedagogicamente e estruturalmente os anseios e demanda da comunidade.

Em resposta às reivindicações do povo, em setembro de 2006, foi inaugurada a escola diferenciada pela qual o povo Kanindé tanto ansiava, onde tomaram consciência de que era necessária a organização para reivindicar real mudança no modelo educativo executado. Assim como com os Kanindé, esse rompimento é perceptível no Brasil, no qual as populações indígenas lutaram por uma educação diferenciada, esse período para (LUCIANO, 2006, p. 19, 20),

[...] Foi um período histórico da luta de resistência indígena no Brasil, por um lado, caracterizado pelo surgimento e pela atuação de lideranças indígenas carismáticas que, com coragem e determinação, enfrentaram as forças colonialistas e integracionistas (Estado e Igreja) que subjugavam os povos indígenas; por outro lado, os povos indígenas, apoiados por alguns importantes aliados (missionários, indigenistas e 20 intelectuais), iniciavam uma longa e bonita caminhada de reorganização, mobilização e articulação política pan-indígena de resistência e de defesa de seus direitos e interesses coletivos [...].

Retrospectivamente, em 1999, instituiu-se a primeira resolução do Conselho Nacional de Educação-CNE, que objetivava a fixação das Diretrizes Nacionais para a Educação Escolar Indígena no Brasil, que surge com normas específicas para o funcionamento pedagógico diferenciado, com o objetivo de atender as demandas coletivas dos inúmeros povos 
indígenas brasileiros, os quais, por sua vez, assumem a direção de grandes mobilizações e organizações sociais de resistência às políticas governamentais impostas aos índios.

As Diretrizes Nacionais para a Educação Escolar Indígena (p. 376-377) têm por objetivos:

a) Orientar as escolas indígenas de educação básica e os sistemas de ensino da União, dos Estados, do Distrito Federal e dos Municípios na elaboração, desenvolvimento e avaliação de seus projetos educativos;

b) Orientar os processos de construção de instrumentos normativos dos sistemas de ensino visando tornar a Educação Escolar Indígena projeto orgânico, articulado e sequenciado de Educação Básica entre suas diferentes etapas e modalidades, sendo garantidas as especificidades dos processos educativos indígenas;

c) Assegurar que os princípios da especificidade, do bilinguismo e multilinguismo, da organização comunitária e da interculturalidade fundamentem os projetos educativos das comunidades indígenas, valorizando suas línguas e conhecimentos tradicionais; etc.

Todos esses objetivos surgem para atender aos anseios das comunidades étnicas, uma vez que cobravam ao Estado um modelo educativo diferenciado que não pautasse a educação com ideologia assimilacionista ou integracionista, as quais funcionaram apenas para o isolamento e o apagamento dos indígenas na sociedade. Eles almejavam uma educação de afirmação e de respeito às pluralidades étnicas, uma educação de reafirmação de identidades e valorização de seus próprios métodos de ensino e aprendizagem, uma vez que a educação para os indígenas não está somente atrelada à sala de aula, pelo contrário, os conhecimentos indígenas estão nas simbologias e representações étnica do povo, logo a escola não tem que apagar esses elementos, e sim utilizá-los como instrumento de ensino para ajudar a fortalecer a identidade dos povos nas subjetividades étnicas.

Portanto, foi através da conquista de direito à educação diferenciada em âmbitos nacionais que emerge a escola diferenciada de Ensino Fundamental e Médio Manuel Francisco dos Santos, a qual surge da necessidade do povo Kanindé de Aratuba-CE, de reforçar a organização sociopolítica do movimento indianista do povo, da saúde indígena, além de resistência na luta pela demarcação da terra, que sempre foi uma das principais causas dos conflitos e das violências praticadas contra as populações indígenas no Brasil, e nos Kanindé não foi diferente, como nos comenta uma liderança indígena, quando perguntamos se houve conflito na conquista da terra e ele diz; "sim houve e ainda existe, pois nos lados da terra ainda há inúmeros posseiros”. Bernando, (Liderança Indígena, janeiro/2016).

Por meio da pesquisa realizada na escola, podemos observar que a educação escolar entre os Kanindé significa resistência, ou seja, é a estratégia utilizada para se manterem vivos, para se afirmarem enquanto índios, de valorizar suas narrativas históricas, suas culturas como seus meios próprios de relacionamentos com as comunidades na qual vivem, como também 
outras comunidades, é a forma de engrandecer seus rituais, bem como seus processos próprios deviver com a diversidade. De acordo com Bonin (2000, p. 2), a educação é:

A afirmação da existência de distintas formas de educar construídas historicamente pelos povos indígenas. A educação indígena compreende os processos pelos quais esses povos garantem sua continuidade, reproduzindo e reconstruindo a identidade, a tradição, os saberes, os valores, os padrões de comportamento e de relacionamento, na dinâmica própria de suas culturas. A educação é um processo que ocorre de modos distintos e por meio de pedagogias e mecanismos próprios em cada cultura. Os povos indígenas possuem espaços e tempos educativos dos quais participam a pessoa, a família, a comunidade e todo o povo. Deste modo a educação é assumida como responsabilidade coletiva.

$\mathrm{Na}$ citação anterior, podemos destacar a importância de compreendermos que a educação indígena Kanindé não está atrelada apenas à forma de aprender, mas, de acordo com Gomes (2016) no processo de ensino e aprendizagem também está ligando as relações sociais e culturais exercidas em comunidade, pois as crianças desde cedo visualizam na figura de seus pais e dos velhos da comunidade, que a cultura e a história estão para além dos muros físicos da escola, uma vez que a escola não tem o papel de formar índios para serem índios, a mesma deve conduzir o processo de aprendizagem demostrando aos seus alunos a história e cultura do povo, mas a escolha de afirmação é do individuo em reconhecer que todo aquele conteúdo exposto faz parte da sua vivência cotidiana, e que esse reconhecimento possa produzir nela significado para praticar isso em suas relações e vivenciá-las na comunidade.

Pensando nesse debate que perguntamos às professoras entrevistadas, Como elas têm percebido a escola influenciando as crianças na formação de sua identidade indígena? Rita nos respondeu que:

Sim, com frequência percebemos, pois sempre organizamos movimentos, rodas de
conversas como projetos realizados dentro da comunidade e o ponto forte desses
projetos é o fortalecimento dos alunos e da comunidade e eu vejo essa presença muito
forte tanto dos alunos como também da comunidade dentro dos movimentos indígenas
na própria aldeia, e que antes não existia tanto. Hoje vejo que nosso dever como
professor é incentivar os alunos pra que eles não terminem os seus estudos e vá
trabalhar em Fortaleza em um trabalho qualquer, mas que eles pensem em contribuir
dentro da comunidade posteriormente. Logo, compreendemos nesse relato a necessidade de se trabalhar com os alunos a importância dos papéis desempenhados pelas lideranças e professores, para que isso possa incentivar o interesse dos estudantes a desenvolver trabalhos dentro da comunidade, uma vez que uns dizem querer ser médicos, enfermeiros e professores, todavia existem outros que dizem não quererem se tornar lideranças, mas seguir na vida acadêmica. Há, ainda, outros que querem ser lideranças e conseguir melhorar a vida da comunidade. Observamos que, independentemente da profissão desejada pelos alunos, o importante é aflorar, por meio da 
educação, o sentimento de coletividade nesses jovens, para que possam deixar as suas contribuição na comunidade, como médico, enfermeiros ou professores, pois a juventude é o futuro dos Kanindé, e a preparação dos mesmos para as futuras lutas se torna algo indispensável. Isto se articula com as reflexões de (BARTOMEU MELIÀ, 1999, p. 15), ao afirmar que,

[...] a construção da alteridade não só tem objetivos específicos numa ou noutra sociedade, mas também métodos próprios [...] entre osmétodos indígenas, um dos principais é a participação da comunidade na ação pedagógica. É precisamente a participação da comunidade, que assegura uma alteridade bem entendida [...].

Portanto, observamos a necessidade de compreendermos a importância das ações coletivas, pois o protagonismo da educação Kanindé não é uma consquista de uma pesssoa, mas de várias como a Terezinha Barroso, Suzenilton Santos, Valdelia Gomes, Nelma Batista, Elenilson Gomes, Suzenalson Santos. Como também Cacique Sotero, Cicero Pereira, Pajé Maciel, José Maciel, José Francisco, os quais se empenharam bastante para a conquista de uma educação diferenciada e que pudesse pautar a história e a ancestralidade como diretrizes pedagógicas.

Nesse sentido Bonin (2000, p. 4) analisa que a educação coletiva pressupõe a "[...] participação na vida cotidiana, acompanhada de perto pelos exemplos e palavras educativas, as novas gerações vão sendo integradas ao coletivo ou a identidade, que é coletiva e dinâmica [...]", complementando a citação anterior a professora Ivoneice pondera que:

Sim, já vejo mudanças por que logo no início, quando eu comecei aqui na escola indígena que não esse prédio, eu ensinava debaixo das árvores nas casas dos vizinhos, a gente percebe a diferença de lá para agora, pois antes muitas crianças cresciam com o entendimento de que não eram índios e diziam que aqui no Fernandes não tinha índios, mais as famílias existentes nas comunidades que dizem que não são índios, mas todos são de uma única família e viemos do mesmo lugar, essas crianças estavam crescendo desse jeito não se reconhecendo enquanto tal, com o trabalho cultural desenvolvido pela escola hoje as crianças, jovens, velhos, ou seja, toda a comunidade diz que são índios.

Portanto, podemos perceber o protagonismo da atuação da educação escolar indígena com o Povo kanindé na afirmação étnica das crianças, pois no relato da professora observamos quando ela diz que, antes da escola, muitas crianças, jovens e até adultos da comunidade não reconheciam sua indianidade, porém após a implantação da escola, bem como com suas políticas pedagógicas voltadas à cultura por meio dos projetos diferenciados, trabalhou-se fortemente com as novas gerações, levando-os a compreender o significado de ser índio e a importância de se reconhecerem em qualquer espaço que for necessário. Com isso reconhecemos o desempenho da Escola Indígena Manoel Francisco dos Santos em fortalecer o 
sentimento de resistência em favor do direito a ser diferente, mesmo com todas as dificuldades em relação ao Estado, o qual não flexibiliza o currículo das escolas diferenciadas, como também a própria gestão escolar que deve atender os anseios da comunidade, respeitando a história e a ancestralidade.

\section{OS PROJETOS DIFERENCIADOS DE EDUCAÇÃO ESCOLAR INDÍGENA ENTRE OS KANINDÉ DE ARATUBA/CE}

Demonstraremos, a seguir, alguns projetos e atividades desenvolvidas pela escola diferenciada, o que possibilitará compreender o processo formativo pelo qual passam os alunos indígenas, uma vez que a escola tem o importante papel de formação cultural dos seus estudantes. Isso nos permitirá entender até que ponto a instituição tem utilizado os espaços possíveis para a resistência e o protagonismo na exercução da proposta diferencida, uma vez que é nesse ponto que encontra a diferença de seu currículo em relação às outras escolas tradicionais brasileiras.

O Projeto Tempo comunidade foi criado por necessidade dos professores indígenas que estavam cursando o MISI PITAKAJÁ ${ }^{5}$, uma que vez que o curso acontecia na segunda semana de cada mês e no interior das aldeias envolvidas na formação, sem que houvessem outros professores para substituí-los. Assim, incrementaram uma nova proposta metodológica para a escola que garantisse o padrão de qualidade de ensino da escola e, sobretudo, o diferencial da escola que é o ensino da cultura e história do povo. Para isso, procuram uma fundamentação legal que viesse a garantir as especificidades da educação escolar indígena, com isso fundamentaram o projeto no artigo 210 da Constituição Federal (Título VIII, Capítulo III, Seção I), que assegura: “O ensino fundamental regular será ministrado em língua portuguesa, assegurada às comunidades indígenas também a utilização de suas línguas maternas e processos próprios de aprendizagem".

Com isso, objetivavam a inclusão dos alunos no convívio da aldeia, compreendendo as relações estabelecidas no cotidiano, para, assim, pensarem seus projetos de vida, os alunos eram organizados em grupos nos quais cada equipe tinha seu tema de pesquisa e seu orientador, todas as temáticas de pesquisa abordavam os contextos locais da comunidade e as principais

\footnotetext{
${ }^{5}$ MISI PITAKAJÁ: é curso superior, onde tem por objetivo formar professores para lecionar no Ensino Fundamental e Médio nas escolas indígenas diferenciadas dos respectivos povos envolvidos na formação. O diferencial dessa formação é que as aulas acontecem no interior das aldeias, e quem diz quem está apto à formação é a própria comunidade, respeitando deste modo a autonomia das comunidades envolvidas, no magistério superior para os povos pitaguary, tapeba, kanindé, jenipapo e anacé, todos envolvidos em busca da qualidade da educação indígena no interior de suas aldeias.
} 
fontes de informações eram as famílias, os troncos velhos e as lideranças. Na semana seguinte, os alunos tinha que apresentar em sala de aula as pesquisas realizadas e os resultados encontrados durante o período da pesquisa. Nesse momento, a escola reunia a comunidade escolar e a comunidade em geral para apreciarem os trabalhos e resultados, na oportunidade dos discentes descreverem suas impressões sobre os relatos e das fontes encontradas.

A partir da pesquisa realizada, podemos reconhecer a importância desse trabalho dentro da proposta de educação diferenciada, uma vez que a integração da comunidade e a escola se torna fundamental na construção eficiente desse processo educativo, como disse Ivoneice, coordenadora pedagógica “[...] que este programa está impulsionando um processo de ensino e aprendizagem de nós mesmos enquanto povo Kanindé [...]", influenciada na autoafirmação das novas gerações, para assim continuarmos a nossa história preservando as tradições.

Oficinas de Artesanatos. Segundo Ivoneice "o artesanato é um importante ponto de identidade que vem fortificando o povo Kanindé, pois não se pode deixar morrer os costumes e as memórias dos troncos velhos", essa proposta surge para garantir a integração e a transmissão do saber, uma vez que isso deve ser passado hereditariamente de pais para os filhos de geração em geração. Com isso, foram implantadas, dentro das escolas diferenciadas, as oficinas de artesanatos, nas quais os mais velhos ensinam aos jovens a confeccionar as peças, como cocás, pulseiras, colares, brincos, os próprios saiotes que são usados em momentos específicos de apresentações, entre outros objetos.

O projeto acontece de duas formas, um no qual os professores levam as lideranças artesãs para as suas aulas na escola, e, em outro momento, os alunos vão até o centro de artesanato da comunidade, que fica localizado na Aldeia Fernandes, onde trabalham homens e mulheres, mas, cada um no seu espaço específico, pois os homens trabalham fazendo peças de madeira, como colheres, maracas, entre outras coisas, já as mulheres trabalham com sementes, penas de aves e o crochê, além de outros materiais.

Dito isso, compreendemos a importância desse projeto, pois essas peças detém um grande significado na representação da identidade de um povo, tal como a cultura, a qual é permeada de símbolos e representações, assim são esses objetos, cheios de significados de extrema importância na memória desse grupo étnico, onde cada um possui uma finalidade tanto para os indivíduos quanto para o grupo. O artesanato é uma forma de manter vivas as práticas culturais desenvolvidas pelos antepassados, por isso a grande relevância da aplicação dessas 
oficinas, como forma de preservar e transmitir para os jovens, para guardarem as práticas e repassarem para seus filhos, e assim sucessivamente.

Jovens Lideranças Indígenas. Conforme nos relata Ivoneice, essa “[...] proposta surge da necessidade em dar continuidade a luta de resistência do povo Kanindé [...]", uma vez que as lideranças estão ficando velhas e morrendo", por isso é de extrema importância preparar jovens para passar adiante as lutas e resistência do povo, esse trabalho é desenvolvido pela escola, juntamente com as lideranças da comunidade, onde o principal objetivo é a formação de novas lideranças da juventude, que tem se colocado mais à disposição na autoafirmação de suas identidades indígenas. Nesses momentos, os jovens têm a oportunidade conhecer a função desempenhada por cada liderança, dentro e fora da comunidade, é interessante, como nos diz Ivoneice, "vver que eles manifestam empenho em quererem ser futuras lideranças, e de atuar em outras profissões, na qual poderão melhorar a vida da comunidade e de seu povo [...]" mantendo a tradição ancestral e preservando os símbolos identitários.

Em nossas visitas na escola, tivemos a oportunidade de observar a relevância e a profundidade que o projeto tem tomado na vida cotidiana desses jovens, uma vez que tem impulsionado uma organização sociocultural e política desses sujeitos, Dessa forma, vemos inúmeros resultados positivos, de modo que os próprios alunos passam a representar a comunidade dos Kanindé em eventos, tanto no Ceará, quanto em outros estados brasileiros, construindo uma bagagem histórica e política. Percebemos isso na fala da coordenadora, quando perguntamos se o projeto tem impulsionado uma organização sociocultural desses jovens:

\footnotetext{
Com certeza, porque nós viemos de todo um processo, desde o período que estamos trabalhando o diferenciado, então a sociedade precisa conhecer a nossa história e quem são os Kanindé de Aratuba, então a escola indígena vem trabalhando para a sociedade ver o crescimento da escola e que assim mesmo tenho o reconhecimento pelo trabalho desenvolvido através das estratégias e metodologias de trabalhos da escola de Aratuba, na formação de jovens críticos e com entendimento de quem são. (IVONEICE, Coordenadora Pedagógica, Janeiro/2016).
}

De acordo com o exposto, esse trabalho tem impactos positivos não somente na comunidade, mas também fora dela, uma vez que esses sujeitos são a próxima geração, logo possui grande importância a reafirmação de sua identidade. Com isso, a sociedade reconhecerá a importância e o excelente trabalho desempenhado pelos professores, alunos e lideranças, ou seja, desta forma irão respeitá-los como sendo diferentes, isso é de grande estima na extinção do preconceito existente em relação à diversidade em suas práticas cotidianas. A professora Rita fala sobre a importância do projeto para a continuação do povo Kanindé, uma vez que se 
torna primordial preparar a juventude para serem as futuras lideranças, a esse respeito descreve que:

Sempre é repassado pelo mais velhos e os troncos velhos, que eles estão se indo e a gente tem que formar essas novas lideranças que elas estejam preparadas para quando chegar esse momento eles possam estar assumindo, por isso consideramos importante os jovens estarem ali trabalhando com eles pra saber como eles fazem para quando chegar o momento o jovens possam ocupar o papel da liderança [...].

No relato, observamos a forma como a professora frisa a importância do projeto, ou seja, reconhecendo que as lideranças um dia vão morrer e que a juventude precisa se apropriar da memória ancestral que hoje eles repassam, para que, assim, o povo Kanindé possa ter sua continuidade, uma vez que a luta é constante em conquista de espaço e direitos na sociedade, espaço esse que é negado cotidianamente, onde sempre é necessário que esses sujeitos se imponham e reafirmem sua identidade o tempo todo, para que seu lugar não seja sufocado e seus direitos arbitrariamente negados, por isso é de extrema relevância a conscientização da população jovem Kanindé da sua responsabilidade étnica e social no futuro para com o seu povo, bem como com os seus ancestrais.

Inclusão digital. Essa proposta incrementa esse conhecimento tecnológico não mais como fonte pesquisa, porém como aula obrigatória no currículo escolar. Os alunos estudam o conteúdo da informática e essa nota vai também para o histórico, isso serve como incentivo para outras disciplinas nas quais é necessário o uso da tecnologia. Este trabalho é desenvolvido não só com apoio da escola, mas com a Secretaria de Educação do Ceará, por intermédio da sua CRED 6- no Maciço de Baturité.

Vemos que essa atividade é de extrema importância na preparação dos jovens para o mundo do trabalho, bem como para a atuação no movimento de resistência e luta pelos direitos indígenas. A escola diferenciada tem, sim, papel de formar nesses indivíduos a cultura indígena, para assim influenciar na construção do caráter indentitário desses sujeitos, dessa forma entendemos que não é pelo fato de que eles aprendem a lidar com essas novas ferramentas que deixam de "ser índios” ou indivíduos detentores da identidade étnica indígena.

Inclusão de disciplinas diferenciadas no currículo. A escola, de maneira protagonista, vem desenvolvendo a inclusão de disciplinas voltadas para a comunidade. Esse conteúdo diferenciado, no qual se faz os debates acerca da diversidade cultural e da especificidade étnica do povo, oportuniza assim ir se marcando a diferença entre a escola indígena e a escola convencional brasileira. Para isso foi preciso se pensar em uma metodologia diferenciada de materiais didáticos, como também a própria formação de professores, uma vez que essas disciplinas foram incluídas dentro currículo pedagógico, portanto precisaria de 
docentes com habilidades diferenciadas na atuação, habilidades não só de didática e de conteúdos, mas que tivessem conhecimentos e engajamento político sobre a cultura e identidade do povo, disciplinas como Direito e Legislação Indígena, Cultura e Arte Indígena, Expressões Corporais e Espiritualidade foram introduzidas no currículo.

Essas disciplinas, na sua base teórica, estão à consulta das lideranças e dos troncos velhos. Isso acontece por meio de visitas nas quais os professores levam os alunos até as casas de determinados sujeitos, como o Pajé e o Cacique, pessoas que foram pionreiras no desbravamento e na defesa dessa história e identidade Kanindé. Os alunos extraem as informações por meio de entrevistas, nas quais dialogam sobre as temáticas com a intenção de apropriar-se das informações repassadas, para assim afirmarem-se no futuro.

Podemos peceber que a escola indígena para o povo Kanindé se tornou um mecanismo de luta e resistência, pois a partir da instituição, investe-se na formação étnica de afirmação das identidades indígenas, tendo em vista os esforços tanto da gestão, quanto das lideranças indígenas, para que o método pedagógico fosse voltado para as questões históricas sobre a ancestralidade indígena, podemos supor que os inúmeros projetos aqui colocados todos assumiam o protagonismo de fortificar a interação entre comunidade escolar e lideranças, para assim contribuir para o crescimento coletivo da comunidade, buscando fortificação da luta e da resistência sempre alerta.

\section{CONCLUSÃO}

Por fim, ao apontarmos o protagonismo da educação escolar indígena com o Povo Kanidé de Aratuba/CE, destacamos que eles foram responsáveis pelos primeiros movimentos educativos voltados para a alfabetização das crianças indígenas, tendo em vista que nas escolas tradicionais do munícipio sofriam inúmeras situações de preconceito. Articulado a isso, outro ponto relevante acerca desse pionerismo dos Kanindé que merece ser relatado é a importância desse movimento educativo para a concientização dos jovens indígenas.

É importante reconhecermos o papel do movimento indígena pela conquista de direitos sociais nunca antes conquistados no Brasil, outra vitória foi afirmação de que existia diversidade no país, diversidade essa que, desde o início, tentaram apagar da história, educando os nativos apenas para mão-de-obra escravocrata e para a reprodução das ideologias do Estado, de exploração das terras e das riquezas, neste sentido a organização dos povos indígenas contribuiu para a desmistificação distorcida da imagem do índio no Brasil. 
Dados os seus limites e possibilidades, constatamos que a comunidade escolar de um modo interdisciplinar busca incorporar os elementos do cotidiano do grupo como método pedagógico de ensino, isso para incentivar a conscientização da população indígena jovem, que com essa globalização subalterna da modernidade, tem deixado de lado práticas ancestrais ensinada pelos mais velhos da comunidade. A escola, enquanto ponto da memória, deve cumprir esse papel de fomentar os laços de indianidade nos jovens, para que a partir do conhecimento de sua história possa se reconhecer sua identidade indígena.

Pensando a temática indígena como sendo algo heterogêneo, é perceptível que a questão indígena no Brasil é muito complexa e formada por inúmeros conflitos, e apesar desse caráter diverso da população indígena em relação à cultura, à língua, à religião, às práticas ritualistas, podemos observar um momento histórico de organização de diferentes grupos étnicos, esse momento de articulação do movimento indígena brasileiro, que se organizou em defesa de suas terras e do direito à vida, tendo em vista que o processo colonizador deixou marcas profundas no imaginário da sociedade brasileira, que hoje se reflete nos preconceitos em relação aos índios no país, marcas essas que até hoje são sentidas por esses sujeitos, os quais foram inferiorizados e marginalizados de políticas públicas do Estado voltadas para as suas necessidade fundamentais.

Esse protagonismo da população indígena foi de extrema importância para a conquista de direitos como a educação diferenciada, saúde e, principalmente, a terra, a qual é fundamental para a existência dos povos indígenas, visto que a terra, desde o início do contato com os portugueses, tem sido uma das principais lutas do movimento indígena, e ainda encontramos inúmeros territórios indígenas no Brasil não reconhecidos pelo governo federal, acarretando assim os inúmeros conflitos entre grupos indígenas e os grandes latifundiários, que expulsaram os índios de suas terras para a exploração das riquezas minerais existentes na terra.

Nesse contexto, de conflitos, avanços e retrocessos, a educação escolar indígena se apresenta como uma importante ferramenta de luta e resistência, uma vez que impulsiona, por meio das práticas pedagógicas, a conscientização da população indígena, a qual é detentora de direitos humanos e direitos sociais. Outro ponto é que a escola surge como estratégia de afirmação da diferença indígena, logo ela cumpre o papel de permanentemente impulsionadora da afirmação dessa diferença em inúmeras situações do percurso histórico do grupo. Pode-se perceber claramente isso no decorrer da pesquisa em relação aos Kanindé. A educação escolar Indígena, portanto, é protagonista da luta, pois com a conquista do direito à educação escolar indígena diferenciada, fortifica-se também a luta pelo reconhecimento étnico do grupo. 
Contudo, a educação diferenciada precisa, ainda, quebrar muitas barreiras para que realmente se torne aquilo que se propôs. Partindo da realidade que estudamos na referida escola, são inúmeras as dificuldades, desde o governo que não propõe medidas efetivas para a consolidação da Lei de Diretrizes de Base para a educação escolar indígena no Brasil, até a Secretaria de Educação do Estado, que não respeita a autonomia dos povos indígenas na execução de seus currículos e de seus processo próprios de ensino e aprendizagem, bem como é problemática a situação que os professores terem de lidar com duplicidade de currículos, porém mesmo com esses desafios podemos afirmar que a escola Manoel Francisco dos Santos resiste e tenta cotidianamente superar esses desafios, com a criação de projetos específicos que envolvem a comunidade, lideranças, professores e alunos, onde coletivamente em inúmeros espaços da comunidade e da escola é criado espaços de transmissão de saberes ancestrais, por meio das memórias dos idosos e jovens, isso com objetivo de fortificar esse sentimento de pertencimento do grupo.

Neste sentido, o protagonismo da educação escolar indígena entre os Kanindé de Aratuba emerge como experiência da disputa por terra, trabalho, saúde, educação entre outros meios mínimos necessários à produção da vida para além do capital.

\section{REFERÊNCIAS}

BONIN, Iara Tatiana; A organização do trabalho pedagógico da escola Kambeba: quando a cultura alicerça o fazer pedagógico, UFB-DF, 2000.

BRASIL. Referencial Curricular Nacional para as Escolas Indígenas (RCNEI). Brasília, 1998. Disponível em:< http://www.cbhcuru.com.br/conheca/ > Acesso em: 22/03/2016.

GOMES, A. O. Aquilo é uma coisa de índio: objetos, memória e etnicidade no Museu dos Kanindé de Aratuba-Ceará. 1. ed. Recife: Editora da UFPE, 2016. v. 1. 406p .

LUCIANO, Gersem dos Santos. O índio brasileiro: o que você precisa saber sobre os povos indígenas no Brasil de hoje. Brasília: SECAD, 2006.

MARTINS, Suerdo Gomes e SANTOS, Suzenalson da Silva. Pelas Veredas da Memória: História, Afirmação Étnica e Organização Comunitária entre os Índios Kanindé, Fortaleza-CE ,UFC, 2016.

MEC. INEP. Diretrizes para a Política Nacional de Educação Escolar Indígena. Brasília: MEC/SEF/DPFE, 1994.

MELIÀ, Bartomeu. Educação Indígena na Escola. Cadernos Cedes, ano XIX, no 49, Dezembro/99. 
MUNDURUKU, Daniel,. O Carater Educativo do Movimento Indígena Brasileiro(19701990), (P. 209 à 224), São Paulo, Paulinas, 2012.

POLLAK, Michael. Memória e identidade social. Estudos históricos, v. 5, n. 10, p. 200-212, 1992.

SILVA, Márcio F. da e Azevedo, Marta M. "Pensando as escolas dos povos indígenas no Brasil: o movimento dos professores indígenas do Amazonas, Roraima e Acre.”. In: SILVA L. da e GRUPIONI, L.D.B. (orgs.) A temática indígena na escola - novos subsídios para professores de $1^{\circ}$ e $2^{\circ}$ graus. Brasília, MEC/MARI/UNESCO. 1995.

SILVA, Rosa Helena Dias da, Movimento Indígena no Brasil e a Questão Educativa; Relações de autonomia, Escola e Construção de Cidadanias, Caxambu, Universidade do Amazonas, , 1999.

SOUZA, Maria Cecilia Cortez Chistiano de. A Escola e a Memória, Bragância Paulista, Editora da Universidade de São Francisco, 1996. 